March - 2005

\title{
Markets, Distance Education, and Australian Higher Education
}

\author{
Ted Nunan \\ Flexible Learning Centre \\ University of South Australia \\ Adelaide, Australia
}

\begin{abstract}
The paper argues that the Australian university system is unstable. There will be significant change as government implements its reform agenda and even more radical change if it moves to new deregulation. The role of distance education in university education needs to be analyzed against this 'market' agenda of government in terms of characteristics of markets and market behavior. After a scan of the current role, the paper looks at two scenarios (regulated and deregulated) for distance education in university teaching and learning in Australia.
\end{abstract}

Keywords: educational markets; distance education; flexible delivery; competition

\section{Introduction}

Australian higher education is about to be changed by a government 'reform agenda' that establishes a market (see also Cummings, Phillips, Tilbrook, and Lowe; Reid; Inglis; Smith; McConachie, Danaher, Luck, and Jones, this issue) for educational goods and services and regulates competition within that market. The starting point of the reform agenda has been the privatization of the university system through government underfunding of operating costs. To survive, universities need to earn income from private capital. For the past ten years the Australian system has been propped up with education export earnings.

The changes underway within Australia are consistent with trends in Western education systems. Gibbons (2004), for example, identifies three principal elements of the new context in which universities operate: "a rightward shift in political thinking; an intensification of competition brought about, in part, by globalisation;" and "a more central role for knowledge in generating the innovations that are needed to meet the risks associated with the intensification of competition." This 'rightward shift' and 'globalisation' have led the Australian government to rely upon competition as the force that will shape the demand for and the provision of education.

This paper looks at distance education as it is changed by, and operates within, educational markets in Australia. It contends that directions and developments in distance education depend increasingly upon market forces and that an analysis of these forces is essential to understanding current changes and possible futures. 
The situation within Australian university education is unstable. A brief scan of current developments in university education and the role of distance education within it are provided before two change scenarios are examined. The first is a form of regulated market proposed by government and outlined in Our Universities: Backing Australia's Future (Nelson, 2003; see also Cummings, Phillips, Tilbrook, and Lowe, this issue), and the second involves a radical 'paradigm change' to open the market to what are currently in Australia non-university providers. The need to address the possibility of radical change is a feature of analysis of the Australian system by writers such as Simon Marginson (2003, 2004) and Glyn Davis (2004).

\section{Australian Higher Education: The current situation with regard to distance education}

Within Australia, there has been little movement in the provision of distance education with institutions that traditionally cater for external students maintaining their market share of the domestic market. The figures for the top six providers (taken from the Department of Education, Science, and Training statistics on all students by state, institution, mode of attendance, type of attendance, and gender for 2003/ 2002) show minor fluctuations in student numbers: 27,474/ 28,871:13,909/ 13,955: 12,307/ 14,126: 9,390/ 9,676: 6,850/ 7,238: 18,737/ 18,446. These fluctuations are against a backdrop of an 8 percent overall growth in full-time distance education students, an 8.8 percent growth in full-time multi-modal students, and a 5 percent growth in internal full-time students for 2003 compared with 2002.

The 'no or limited growth' scenario for domestic external students has meant that distance education is of little strategic interest to institutions in their quest to gain income through new markets or by gaining a greater share of existing markets. There is, however, strategic interest in maintaining market shares of domestic internal students by ensuring that study arrangements are convenient and enable students to 'earn and learn.' Many institutions have therefore added to their existing 'design configuration' (the mix of technology, administrative arrangements, and people) (Gibbons, 2004) to develop more flexible delivery approaches (Nunan, 2000), while at the same time maintaining face-to-face as the predominant mode. This has meant the provision of parts of a program by distance or online education or at the very least the use of distance teaching techniques within courses or programs.

In Australia, the enrollment category of mixed mode records instances where students use a mix of internal and external studies. This provides a measure of flexibility at a macro level as it enables student choice about how frequently they will need to attend at a campus. The use of micro in-course mechanisms of introducing flexibility using distance education or online teaching and learning techniques is much more difficult to measure as three categories have been identified (Web supplemented, Web dependent, and fully online) and institutional and national figures are not available.

The provision of mixed mode attendance within a program has seen major changes in demand and provision. In New South Wales, changes between the 2002 and 2003 mode of attendance patterns show that the total of part- and full-time external and multi-modal students went from 28,699 to 58,785 - an increase of some 105 percent. Closer inspection of the figures reveals that the changes represent a number of universities providing external mode within multi-modal attendance - for example, Macquarie University for 2002 had 79 and 895 full- and part-time external with 350 and 160 full- and part-time multi-modal students, while for 2003 the corresponding figures were 78, 742, 291, and 3,465; the figures for the University of New South Wales were 254, 1531, 0, and 0 for 2002 and 212, 858, 0, and 5,420 for 2003. Institutions with 
existing external delivery capacity have used this to provide more flexible arrangements for studying programs at their institutions.

New forms of 'distance education' have become integrated into the delivery processes of universities as 'flexible delivery'. Universities are undergoing a paradigm shift with regard to the provision of teaching and learning - their first decision is more likely to be what type of variant of fifth generation intelligent flexible learning (Taylor, 1999, 2001; see also Reid; Smith, this issue) is needed, rather than whether either traditional internal face-to-face or distance teaching should be used. Indeed, the changes to distance education are such that it is arguable whether it is useful to consider it as a distinctive and organizational entity (King, 2003).

Distance education has but a small and tangential role to play in the main game for Australian higher education, which is generating income from international enrollments. Currently international students make up nearly one in four of all Australian university students and contribute AUS \$5 billion to the system. There are predictions for further expansion. Vidovich (2004) comments upon this situation, noting that Australian universities:

... are heavily into the 'business' of international marketing, and this emphasis is set in a context of reduced Commonwealth Government funding, creating pressures for universities to actively seek private sources of income, especially from overseas (p. 344).

So important has been this source of funds to the economic survival of particular institutions that within them the national and local have become driven by the global.

Conventional distance education has not been part of exporting education. Where students are taught in their home country the model has been largely one of an Australian satellite campus or of 'education centers' through partner institutions. However, the products of distance education in the form of printed course guides and their resources often play a role in defining the syllabus of the area and in assuring the quality of the face-to-face teaching and learning experiences provided by a partner institution. This use of distance teaching materials in conjunction with local tutors enables the capacity to reach wider in-country markets and has assisted in gaining income for some institutions.

\section{The Australian Higher Education Market: Charting the changes ahead}

I move now to look at the changes that will come with the regulated market arrangements announced by government and speculate upon the possible impact of changes that would flow from a deregulated market.

In terms of a regulated market, Marginson (2004) summarizes the agenda set out in Our Universities: Backing Australia's Future (Nelson, 2003) in the following terms:

... [It] establishes full fees, supported by a voucher-like income contingent loans scheme on the Friedman model for up to $35 \%$ of students in undergraduate courses. For other students, it allows universities to vary their Higher Education Contribution Scheme (HECS) charges as they see fit, up to 25 percent higher than the present standard HECS rates, or down to zero, so that the places would 
be funded just by the government grant. Thus the HECS, which was originally intended as a standard payback charge to defray costs with a minimum economic impact on the student, begins to look more like a market price. The Nelson program also extends the new tuition loans (aptly named FEE-HELP) to universities in the private sector, which makes the private higher education sector economically viable for the first time (p. 6).

Marginson believes that such changes will constitute a "key moment" for the higher education system, as it will be "the first time that the full scale Hayek-Friedman model has been implemented into undergraduate education in Australia, and one of the first times in the world." For postgraduate research and coursework studies, market conditions had already been established as the start of a program of competition and pricing.

A deregulated market will be formed if the Australian government changes its definition of the term 'university' and allows 'teaching only' institutions to award university degrees. Currently in Australia a university must conduct teaching and engage with "the creation of new knowledge through research, and original creative endeavour" (Ministerial Council on Education, Employment, Training, and Youth Affairs, 2000, n.p.). Davis (2004) argues that deregulation will create a new range of private and public teaching only institutions and open the Australian system to education exporters from other countries. This creates new market conditions never before experienced within Australia with 'teaching shops,' Internet providers, satellite campuses, and other 'design configurations' competing for a share of the market for university degrees. The future directions and uses of 'distance education' in Australia depend upon whether deregulation takes place or not.

Before I move to speculate upon futures for distance education, it is useful to identify broad directions for distance education that are consequent upon markets and market behaviors. A useful starting point in the analysis of markets is provided by Marginson (2003):

Markets incorporate five distinct features: a defined field of production and consumption: competition between producers; identifiable products (commodities); prices and monetary exchange between producers and consumers; and the human behaviours and values - entrepreneurship and minimisation in production, utility-maximisation in consumption, contractual relations and so on - consistent with economic self interest. Real life education systems normally incorporate some but not all of these features of markets in a developed form. Higher education systems typically consist of a set of producer institutions ('the market') that together participate in several interlocking markets based on distinct products: undergraduate education, research degrees, research and consultancy, other services (p. 7).

The next section of the paper takes these five features of markets and comments upon the operation of distance education with regard to each of the features.

\section{What Role for Distance Education in a Market Driven System?}

Much of the analysis of the future of distance education has been by educationists who tend to highlight particular drivers of change (see also McConachie and Danaher; Cummings, Phillips, Tilbrook, and Lowe; Reid; McConachie, Danaher, Luck, and Jones, this issue). For example, much is written about the unprecedented demand for higher education, the capacities of new 
technologies that are being used to deliver education, and new methodologies that accompany such technologies. Analysis of this situation results in conclusions such as "competition in education on an international and national basis will become the principal determinant of the success or failure of institutions” (Turoff, 1998, n.p.), or that the confluence of these forces will see e-learning in the form of online delivery as a potential solution to the situation. Bonk (2004), for example, writes about the Perfect E-Storm (from emerging technology, enormous learner demand, enhanced pedagogy, and erased budgets) and sees technology as a solution for maintaining quality and achieving more with less. Twigg (2003) sees improving quality, reducing costs, and meeting demand connected with radical changes in institutional practices. She contends:

Currently in higher education, both on campus and online, we individualize faculty practice (that is, we allow individual faculty members great latitude in course development and delivery) and standardize the student learning experience (that is, we treat all students in a course as if their learning needs, interests, and abilities were the same). Instead, we need to do just the opposite: individualize student learning and standardize faculty practice (n.p.).

These works provide insights into facets of the situation and often take normative positions based on a number of social values. There are few analyses that bring together features of markets and put the position that it is market behavior in response to a set of conditions that shapes possible choices for action. The notion that educational purposes and directions are a function of Adam Smith's 'invisible hand' which operates in ways consistent with economic self-interest is not an attractive one for educationists.

In what follows the concept of a market, its features, and its behaviors provide an integrative framework for analysis. The five distinct features cited by Marginson (2003) are taken in turn.

\section{Markets Have a Defined Field of Production and Consumption}

Technically, any university can define the field of production that it wishes to exploit or specialize in, provided that it alone can confer the degree. While the end-point 'field of production' is a degree, the mechanisms to achieve this for consumers can involve producing other products. In the case of distance education, such products are course guides and readers, assessment tasks, and specific services associated with external studies. In Australia, consumption of such products has been mainly for postgraduate coursework or professional upgrading degrees.

The conventional role for distance education has been to provide external studies toward recognized degrees for those consumers who could not, or chose not to, attend the institution. There have been various attempts to define cost relationships between such production and consumption, and conclusions vary according to how costs are attributed, the richness of the services supplied including those that use communications technology, the costs of the teaching and marking, and whether the activities maximize economies of scale. Hülsmann (1999) reports that, on a cost per student basis in five industrialized countries, distance education institutions can operate at between 25 and 50 percent of the cost per student in a conventional university.

The move to mixed mode studies has seen a different pattern of consumption where distance education is used by internal students as a convenience - it allows students to earn and learn by managing time to suit their particular circumstances. This move to 'convenience' for internal students means that design configurations will need to use distance or online techniques and 
consumer expectations will drive institutions to compete with regard to flexibility in the provision of studies. This will lead to considerations of costs of introducing flexibility and cost benefit analysis by institutions. Particular educational products and services products may be outsourced using partnership arrangements in efforts to gain a quality or cost advantage.

Consequently, distance education processes and products may provide the key to being able to take greater market share (of either or both internal and external students) in an area by 'tailoring' costs and prices to undercut competitors. Cutting costs can be by combinations of outsourcing and disaggregation of course delivery arrangements.

\section{Markets have Competition among Producers}

Market competition involves forces such as the threat of new entrants, the bargaining power of customers, the bargaining power of suppliers, the threat of substitute products or services (where applicable), and the jockeying among current contestants (Porter, 1991). Institutions need both to defend against these forces and to influence them in their favor. The regulated system uses the notion of a government sponsored 'learning entitlement' for students to 'spend' among suppliers, while a deregulated system would have a complex price point and other market competition behaviors.

The threat of new producers entering the market for coursework taught degrees is a consequence of the radical deregulation option that may be taken up by government. In Australia the brake upon private capital entering the market is that awarding a university degree can be done only by institutions that satisfy conditions about teaching and research infrastructure and research activity - with this brake removed, 'free trade' in the provision of teaching services will radically change the institutional landscape. If teaching only private producers are given the capacity to award degrees, their 'institutional costs' are likely to be less than those of conventional universities and this could provide a price point advantage in a deregulated market.

Distance education and online delivery processes bring a different form of competition among producers. While 'branding' (see the next subsection) is a function of institutional standing, it can also be a function of teaching and learning excellence made highly visible through distance and online teaching materials. Competition for consumers is made possible as the consumption of superior teaching is a relatively simple matter of changing to a different address on the Internet or the postal address of a new university. Also, it is likely that such competition will be protected by competition 'rules' and students will be able to trade their 'academic currency' (learning entitlement) against a new course from another institution as they search for better subsidies, lower cost courses, higher quality services, better brand names, and so on. Providers of distance education will work to make course switching easier in an attempt to increase demand for their courses or parts of their programs. That is, the market will include parts of a degree program as well as the degree itself.

Distance education providers will balance the 'poaching' and 'loyalty' factors according to their market position and marketing skills. An institution would wish to encourage 'loyalty,' so that students undertake all courses of a degree at that institution, and at the same time maximize 'poaching,' so that students who start a degree elsewhere transfer to the institution. Encouraging 'loyalty' by giving subsidies (by designing 'frequent flyer point' schemes for recruiting others or a sliding scale of subsidization of student costs depending on 'customer loyalty factors') and 'poaching' (making sure that your brand name has high employment or professional advancement 
value and making it available for students who complete one third or more of your degree) will increasingly be used as competition for students becomes greater.

Distance education (and online delivery processes) can be used to create different forms of competition among producers within the market. Given the trend to convenience through mixed mode studies, there will be pressure on institutions to deal with loyalty and poaching, especially where program rules allow the substitution of studies from another institution. Some of the transfer arrangements will be managed through groups of institutions forming cartels (but operating within competition guidelines), so that students will have the advantage of wider choice but from within a managed set of alternatives.

\section{Consumers in a Market Seek Identifiable Products}

Educational markets are distinctive, in that consumers cannot get a complete picture of what they are purchasing as they are yet to experience the teaching and learning opportunities that they will be undertaking. This means that consumers purchase a 'brand' and if the brand does not meet their expectations they seek to transfer among institutions.

While the visibility of the teaching and learning products gives signals to consumers about the standing of the producer, it is the teaching and the support for learners, not the information per se, that differentiate an institution from others. This places service to students as the key factor in a mature market. There will be a short-term valuing of resources and platform advantages by consumers, but these will be significant in the long term only where they are an integral part of a service culture of learning and supporting learning. Consequently, some suppliers are willing to make the information in their courses open and available to all, based on the belief that only they can provide the level of service to match the information product, thereby realizing its value.

Distance education suppliers will increasingly focus upon the service requirements of external students and sharpen this focus to the specific requirements of niche markets. As with banking and other service sector institutions, the mix of online and face-to-face service for students with teaching and learning will be central to the competitive standing of an educational institution. Attempts to identify the service components (through student charters, service agreements, and the like) will become part of the information about delivery processes and will influence consumer choice. Distance teaching materials and student support arrangements will be increasingly used to define services available to internal students.

\section{Markets Facilitate Price Determination and Monetary Exchange between Producers and Consumers}

Value for money can be a direct function of lower tuition charges, better and newer communication technologies, and other services, and through lower opportunity costs (that is, achieving a degree in a shorter time). Subsidies provide more to students for each dollar that they spend at a particular institution. Price points for tuition charges are important in markets, and institutions may work to provide a 'stripped down' version of the teaching and learning experience in an effort to gain market share. Writing about changes in the United States system, Levine and Sun (2002) note:

The bottom line is that today's older adult students are bringing their consumer attitudes to higher education. They seek four things from their colleges - 
convenience, service, high quality and low cost. They will not pay for activities and services they do not use, for hiring faculty to offer elective courses they will not take, for buildings such as a chapel or student union that they will not frequent. They are asking for a stripped down version of high[er] education, absent of extras (n.p.).

Government intends that price signals will become clearer through a loan and repayment via taxation mechanisms and the student learning entitlement. A key initiative here is to have secure, Web-based access via a unique student identity number that will set out the bank style 'education account' of remaining entitlement and charges. Consumers will have information that will enable them to compare options and choices about charges arising from their future studies, and this is seen as part of the infrastructure that is necessary to develop a national market in higher education.

There will be great pressure upon distance education providers to decide whether to maintain parity of esteem between distance courses and face-to face courses by having the same price point for both or to have a cost differentiation which reflects particular economies that can come from using distance education techniques and technologies. Another way of looking at this situation is to decide whether there is market advantage in having reduced distance education costs cross subsidizing face-to-face delivery costs.

\section{Market Behaviors Result from Operating According to Perceptions of the Market}

Both providers and consumers operate according to their perceptions of the market. Because information about a degree is generally cast in terms of 'producer specifications' (its content, the type of teaching that is received, the rules and regulations associated with achieving the degree), judgments about the product are often made on the basis of producer or input characteristics (for example, staff qualifications and research output, producer processes and quality systems, selectivity of students). This is often termed 'institutional reputation' or 'brand.'

For distance education, quality course materials, service culture, and identifiable subsidization will interact in ways that produce market advantage. Selectivity for distance education is not attained through the exclusion of students - instead, the quality of a course or program provided by distance education is less about who interacts with the individual as a student and more about the total nature of the student experience. With formal education, part of the purchase is about 'whom you sit with' in lectures and tutorials; for distance institutions a market signal for quality comes from the type of service culture that surrounds the student experience. For distance education, value for money becomes a key factor in the selection of an institution, program, and course.

Value for money and perceptions of it can flow from economies of scale, which can bring lower student charges and subsidized services in key areas such as ease of registration and credit transfer, telecommunications, and library services. Personalized experiences can be maintained where large enrollments are broken down into smaller 'activity groups' linked to an institutional 'tutor' so that advantages of small group 'membership' can be retained. The provision of comprehensive course materials within the tuition costs can be a major advantage, as it reduces the costs associated with the purchase of texts, travel to libraries, and other communications charges. Institutions will exploit 'value for money' subsidies that impact upon consumer perception and satisfaction with the institution and their experience of studies. 
Institutions will be engaged in careful analysis of the relationship between fixed and variable costs when attempting to exploit economies of scale and a mix of service provision that involves technology. It is commonly agreed that the cost structure of distance education is one of high initial fixed costs with low variable costs, but that the latter are altered by the choice of delivery medium. Any strategy that requires significant technical support for students or allows greater access by students to academics will, in a developed country, cause variable costs to increase and may disrupt the economies of scale derived from other areas. More importantly, a balance between fixed and variable costs will impact upon consumer perceptions, and institutions will be engaged in greater monitoring of student satisfaction about their study experiences.

To use distance education in a market, it will be necessary to have both economies of scale within institutional infrastructures (that is, special delivery arrangements for large numbers of distance education students catered for by the institution) and programs that have 'scalable delivery processes' to generate good profit margins. Institutions that position themselves to students as a mix of 'clicks and bricks' and market their student service-oriented culture will reap long-term benefits. Getting the right mix of technology and services for external, internal, and international students, and capturing this within the institutional brand, will be essential in a competitive market.

\section{Conclusion: The future of distance education in Australian higher education}

This paper has argued that 'distance education' will be reduced to its economic purposes defined by market conditions of supply, demand, and competition. The current major providers of distance education in Australia with 10,000 or more students are likely to make strategic gains in the longer term and through their focus upon recruiting staff who are skilled in distance education/ online technologies to gain greater shares of a relatively small and stable market.

The trend toward using distance education techniques to improve the flexibility in delivering teaching and learning will continue, and this will be through both mixed mode enrollments and the use of online approaches within courses. If Australia moves to mass higher education targets of 50 percent of the secondary school population, this trend for catering for 'earner learners' will intensify, and with price differentiation becoming a factor influencing student choice there will be growing pressure on institutions to compete in the provision of flexible learning. This competition will mean that institutions will increasingly focus upon analyzing the costs of providing this flexibility and evaluating whether such costs are warranted given the market share that results. Universities will focus upon business cases for new programs, and cost models for different levels of delivery will have center stage in program approvals processes.

If the market is deregulated and a new range of providers is able to confer university degrees, there will be niche providers working to undercut traditional universities in high demand, high profit areas such as executive management, specialist computer science, and law. Free trade arrangements open the potential for imports and exports in education that respond to global demand and global cost and price structures - for example, distance teaching universities such as the University of Phoenix might seek to establish a presence in Australia and provide 'shop face' facilities for outsourcing elements of their delivery processes.

Because of the unstable condition of Australian higher education, the future for distance education is not easy to predict. Gibbons (2004) identifies static and dynamic competition: static competition works within the current 'design configuration,' while dynamic competition attempts 
to foreshadow the next 'design configuration' that will arise through changes in technology and other market conditions. Australian university education is undergoing reorganization, and current 'design configurations' are moving to feature flexibility. Dynamic competition may come into play with deregulation, and radical and new design configurations will be necessary - the familiar forms of organizations and ways of working may be overturned, with a greater emphasis upon responding to competition for private capital in new markets based upon free trade deals.

Australian universities would be well advised to consider both static and dynamic competition by at least maintaining their existing capacities in distance education, as it represents a reservoir of skills and infrastructure arrangements that can be used to make adjustments to delivery processes to suit future changes to education markets.

\section{References}

Bonk, C. (2004). The Perfect e-Storm: Emerging technology, enormous learner demand, enhanced pedagogy, and erased budgets, Part 1. The Observatory on Borderless Higher Education, 23.

Davis, G. (2004). Tiers or Tears? The regulation of Australian higher education. The Inaugural Melbourne Politics Lecture. November. Department of Political Science, University of Melbourne: Australia.

Gibbons, M. (2004). Innovation in a New Context. Paper presented at the general conference of the Organisation for Economic Co-operation and Development Institute for Management in Higher Education. September 13-15. Paris, France.

Hülsmann, T. (1999). The costs of distance education. In K. Harry and H. Perraton (Eds.) Education Through Open and Distance Learning. Vol. 1 (p. 72-84). London: Routledge and the Commonwealth of Learning.

King, B. (2003). Has Distance Education a Future? Keynote address: Cambridge Conference on Open and Distance Education, September 26-28. Maddingly Hall, Cambridge: UK.

Levine, A., and Sun, J. C. (2002). Barriers to Distance Education. Washington, DC.: American Council on Education Center for Policy Analysis.

Marginson, S. (2004). They Make a Desolation and They Call it F. A. Hayek: Australian universities on the brink of the Nelson reforms. Australian Book Review, 260. 28 - 35.

Marginson, S. (2003). Markets in Higher Education: National and global competition. Radford Lecture presented at the New Zealand Association for Research in Education/ Australian Association for Research in Education joint conference, November 29 December 3. Auckland, New Zealand.

Ministerial Council on Education, Employment, Training, and Youth Affairs (2000). National protocols for higher education approval processes. Protocol 1: Criteria and processes for recognising universities. Retrieved February 23, 2005 from:

http://www.dest.gov.au/highered/mceetya_cop.htm 
Nelson, B. (2003). Our Universities: Backing Australia's future. Canberra, ACT: Commonwealth of Australia.

Nunan, T. (2000). Exploring the concept of flexibility. In V. Jakupec and J. Garrick (Eds.) Flexible Learning, Human Resource and Organisational Development: Putting theory to work (p. 47-66). London: Routledge.

Porter, M. E. (1991). Michael Porter on competition and strategy. Harvard Business Review, 90079.

Taylor, J. (2001). Fifth generation distance education. e-Journal of Instructional Science and Technology, 4(1). Retrieved February 23, 2005 from:

http//www.detya.gov.au/highered/hes.htm

Taylor, J. (1999). The Death of Distance: The birth of the global higher education economy. $e$ Journal of Instructional Science and Technology, 3(1), 6 - 11.

Turoff, M. (1998). Education, Commerce and Communications: The era of competition. Association for the Advancement of Computing in Education. Retrieved February 23, 2004 from: http://eies.njit.edu/\%7Eturoff/Papers/webnettalk/webnettalk.htm

Twigg, C. (2003). Improving Learning and Reducing Costs: New models for online learning, Educause Review, 38(5), 28 - 38. Retrieved February 23, from:

http://www.educause.edu/pub/er/erm03/erm035.asp

Vidovich, L. (2004). Global-national-local dynamics in policy processes: A case of 'quality' policy in higher education. British Journal of Sociology of Education, 25(3), 341 - 354. 